\title{
Histopatologia de raizes de pimenta-do-reino (Piper nigrum L.) parasitadas por Meloidogyne incognita
}

\author{
Resumo
}

Procedeu-se a observaçôes histológicas de raízes de pimenta-do-reino, variedade Singapura parasitadas por Meloidogyne incognita. A penetraçāo das larvas de segundo estádio. o mecanismo de formação das células gigantes, etapas do ciclo de vida do nematóide, suscetibilidade e outros aspectos biológicos envolvendo o complexo hospedeiro $\times$ parasita foram estudados.

\section{INTRODUÇĀo}

As espécies de nematóides das galhas, filiadas ao gênero Meloidogyne Goeldi, 1887. determinam graves alteraçōes nas raizes das plantas suscetíveis, tão logo consigam nelas se estabelecer. As conseqüências patológicas decorrentes do parasitismo vão desde simples deterioração mecânica, originada pela migraçăo do nematóide através das células vegetais, até complexos efeitos reciprocos envolvendo o hospeiro e o patógeno (Sasser, 1971).

Uma das mais conhecidas reações das plantas infetadas por nematóides das galhas é a formação de células gigantes nos seus tecidos condutores. A presença de sincício nas plantas parasitadas é um fenômeno constante na relação hospedeiro $x$ parasita dos nematóides pertencentes à família Heteroderidae, bem assim para alguns nematóides da família $T y$ lenchidae (Endo, 1971).

As profundas alterações citológicas verificadas no curso do desenvolvimento dos sincicios têm conduzido os pesquisadores à elaboração de pelo menos duas teorias elucidativas do mecanismo de formação daquelas estruturas. Segundo Endo (1971) a primeira teoria surgiu após as pesquisas de Kostoff \& Kendall, em 1930, ao estudarem a anatomia das raízes

\author{
Francisco das Chagas de Oliveira Freire $\left(^{*}\right)$ \\ Antônio Valeriano Pereira dos Santos (*)
}

de hibridos de Nicotiana parasitadas por nematóides das galhas. Aqueles autores concluiram que os sincícios se formavam através de dissoluçōes das paredes celulares adjacentes, seguidas de coalescência dos conteúdos celulares. Não obstante a aceitação desta teoria até o presente, um outro mecanismo foi sugerido. em 1969, por Huang \& Maggenti (1969a, 1969b). Estes autores ao estudarem o parasitismo de M. javanica em raizes de Vicia faba concluiram que os sincícios se formavam a partir de sucessivas mitoses de uma célula diplóide original, sem a ocorrência de citocinese. A possibilidade de que os sincícios teriam sua formação e desenvolvimento pela combinação de fusōes celulares e mitoses sincronizadas, na ausência de citocinese, foi sugerida por Bird (1974). Aliás, mitose no interior de células gigantes já havia sido relatada em trabalho de Krusberg \& Nielsen (1958).

Inúmeros outros distúrbios têm sido evidenciados após a penetração nas raízes por larvas de segundo estádio de nematóides do gênero Meloidogyne Goeldi, 1877. Referidos parasitas secretam uma substância que incita a ocorrência de hipertrofia e hiperplasia nos tecidos infetados. Segundo Krusberg (1963) as galhas das raizes resultam de uma hipertrofia e hiperplasia dos parênquimas cortical e vascular, do periciclo e células endodérmicas que circundam as células gigantes bem como pelo aumento de volume da fêmea.

O trabalho em apreço teve por objetivo estudar aspectos envolvendo o complexo Piper nigrum - $M$. incognita, com o intuito de esclarecer as alterações decorrentes desta interação.

(•) - Centro de Pesquisa Agropecuária do Trópico Úmido, Belém.

(") - Divisão de Fitologia da Ceplac (Cepec), Itabuna, Bahia. 


\section{Material e mÉTodos}

OBTENÇÃO DO INÓCULO E INOCULAÇĀO Como inóculo foram utilizados ovos obtidos a partir de ootecas retiradas de raizes de tomateiro, variedade Santa Cruz, multiplicados durante 4 meses em vasos de argila de $16 \times$ $22 \mathrm{~cm}$, contendo uma mistura de terra e areia na proporção de 2:1, previamente esterilizada em autoclave a $121^{\circ} \mathrm{C}$ durante 2 horas, e infestada a espécie $M$. incognita, originada de uma única ooteca. Para a dissolução das ootecas e conseqüente soltura dos ovos, adotou-se o método de Hussey \& Barker (1973), ligeiramente modificado por Freire (1976). Em seguida, a concentração de ovos foi calculada com o auxilio da câmara de contagem de Peter.

Foram usadas 20 plantas jovens de pimenta-do-reino, variedade Singapura, com 3 meses de idade, mantidas individualmente em vasos de argila de $14 \times 18 \mathrm{~cm}$, contendo uma mistura idêntica à mencionada anteriormente. Do total de plantas usadas 10 foram inoculadas com 3.000 ovos e 10 atuaram como testemunhas. Os ovos foram colocados em 3 diferentes pontos do sistema radicular a uma profundidade de $2 \mathrm{~cm}$.

COLETA E PREPARAÇÃo DO MATERIAL PARA os ESTUdOS HISTOLÓgicos - As observaçōes histológicas de raízes de pimenta-do-reino parasitadas por $M$. incognita foram realizadas a partir de cortes de galhas e extremidades de raizes coletadas 40 dias após a inoculaçăo. Tanto as raízes inoculadas como as testemunhas logo após a coleta foram fixadas em FAA $50 \%$. A seguir, foram desidratadas em uma série de álcoois e depois incluídas em parafina e cortadas em micrótomo rotativo na espessura de 10 a $12 \mu \mathrm{m}$ nos sentidos transversal e longitudinal. Os cortes foram corados com safranina e verde rápido, segundo Johansen (1940), e montados com bálsamo do Canadá.

\section{RESUlTADOS}

As observações histológicas realizadas a partir da região terminal das raízes permitiram a visualização de larvas de segundo estádio, localizadas no pleroma e orientadas na direção axial da raiz, normalmente associadas a células gigantes em desenvolvimento incipiente (Fig. 1). Em alguns sincícios foram encontra-

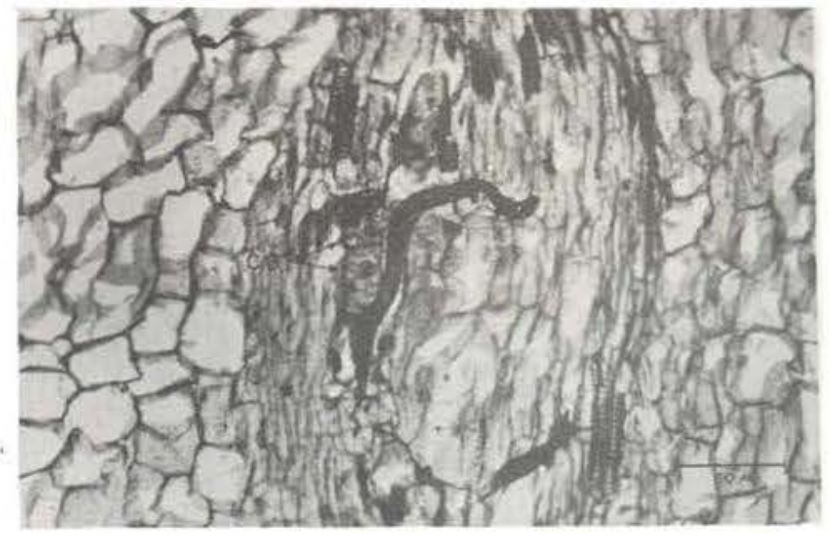

Fig. 1 - Secção longitudinal mostrando larva de se'gundo estádio $(\mathrm{L})$ associada a células gigantes em desenvolvimento incipiente (CG).

das, freqüentemente, células gigantes bastante distintas em tamanho. Muitas destas células apresentavam, em determinadas regiōes, paredes em início de formação evidenciando uma tendência à expansão lateral $e$ aparente englobamento das células adjacentes. Dentro da massa nuclear, destacavam-se numerosos núcleos hipertrofiados e membranas acentuadamente distintas. Alguns nucléolos exibiam um halo bastante translúcido circundando-os de modo a torná-los distintos do restante da massa nuclear (Fig. 2 e 3).

As células gigantes de um mesmo conjunto variavam notavelmente quanto ao aspecto da densidade citoplasmática, sendo encontradas com freqüência células em plena vitalidade ao lado de células em nítido processo de de-

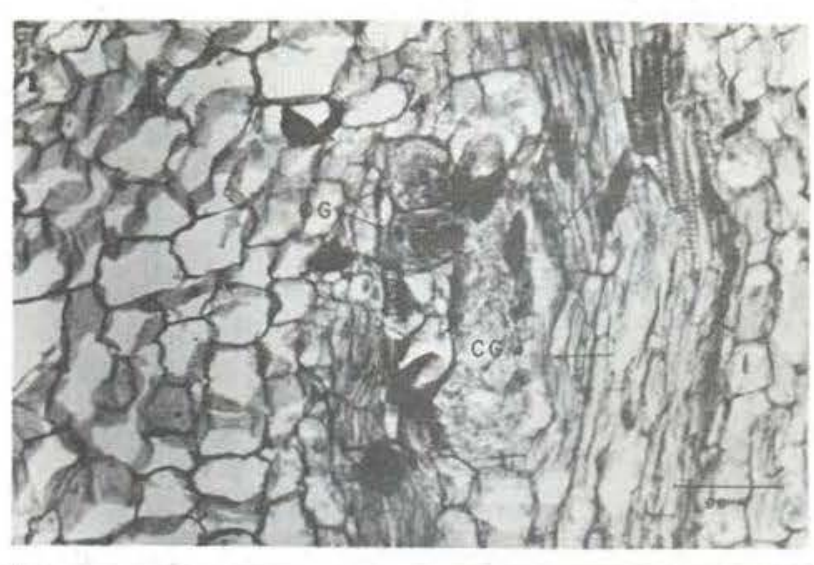

Fig. 2 - Células gigantes (CG) distintas em tamanho evidenciando áreas de formação da parede celular (setas). 


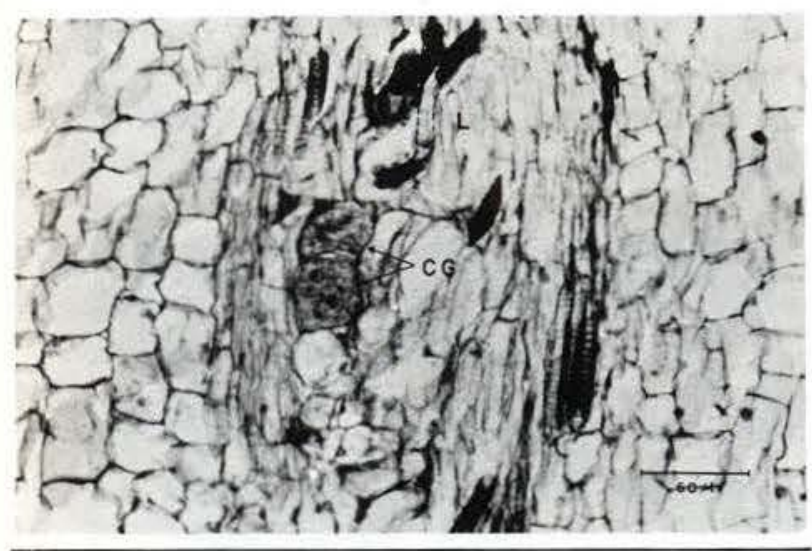

Fig. 3 - Larva de segundo estádio (L) associada a células gigantes jovens (CG) mostrando proeminentes núcleos com nucléolos circundados por halo translúcido.

generescência. Nas células gigantes mais jovens o citoplasma extremamente denso exibia inúmeros núcleos com proeminentes nucléolos. evidenciando uma elevada atividade metabólica daquelas células na elaboração de nutrientes para a fêmea adulta do nematóide. As células em degenerescência, por outro lado, apresentavam citoplasma hialino destituído de núcleos e com distintas desintegrações das paredes celulares. Contudo, tanto as células em atividade como as em degenerescência possuiam forte espessamento secundário das paredes em virtude de abundante material celular depositado em contato com a sua superfície interna. Nas células gigantes destituídas de depósito celular, entretanto, as paredes celulares apresentavam-se relativamente delgadas. Próximo às células gigantes o xilema persistia aparentemente normal (Fig. 4) .

Em secções histológicas longitudinais foram observadas fêmeas jovens e adultas associadas a conjuntos de células gigantes dispostos ao longo do cilindro vascular. As fêmeas normalmente mostravam bulbo esofagiano bastante desenvolvido, ao que parece caracterizando uma intensa atividade parasitária. A despeito de terem sido encontradas várias fêmeas no interior de uma mesma galha, cada uma delas associava-se a apenas um conjunto independente de células gigantes, nunca tendo sido encontradas duas ou mais fêmeas associadas a um único conjunto destas células. As células gigantes ocorrem em grupos radialmente dispostos à cabeça da fêmea, em número de duas a nove, com predominância de quatro células. Algumas vezes chegam a ocupar todo o diâmetro do cilindro vascular aparentemente determinando o colapso deste. A ocorrência de células gigantes no tecido cortical não foi observada.

As fêmeas normalmente localizavam-se no córtex, ligeiramente inclinadas em relação ao eixo da raiz, às vezes quase paralelas, mas raramente perpendiculares ao eixo radicular. A parte anterior da fêmea adulta mostra-se embutida no cilindro vascular, com a cabeça bem colocada entre as células gigantes. O exame do material estudado não permite afirmações quanto aos possíveis locais de alimentação das fêmeas adultas. Entretanto, em algumas situações a fêmea parecia alimentar-se com o estilete entre as células gigantes (Fig. 5).

A parte posterior da fêmea fica situada no córtex radicular onde ocorre a deposição dos ovos. Em tais situações observa-se o xilema em contato com as células gigantes e com a câmara da fêmea, além do floema justaposto às células gigantes. A massa de ovos mostrase isolada dentro do tecido cortical sendo circundada por uma camada escura, constituindo uma verdadeira câmara de incubação (Fig. 6 e 7).

Os ovos são depositados no interior da ooteca sem uma arrumação regular dos mesmos. Aparentemente, a eclosão das larvas

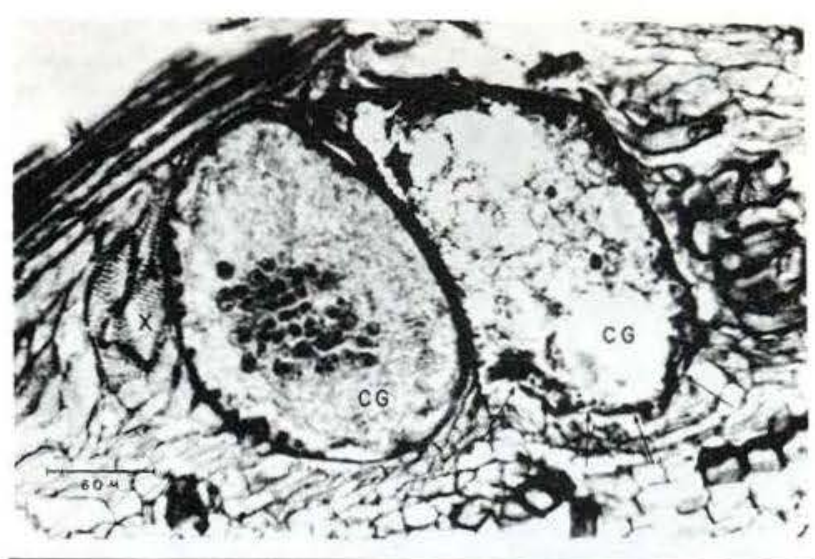

Fig. 4-A esquerda célula gigante (CG) exibindo denso citoplasma e proeminente massa nuclear. A direita célula gigante em degenerescência com citoplasma hialino e áreas da parede celular em dissoluçāo (setas). O xilema $(x)$ mostra-se resistente ao englobamento pelas células gigantes. 


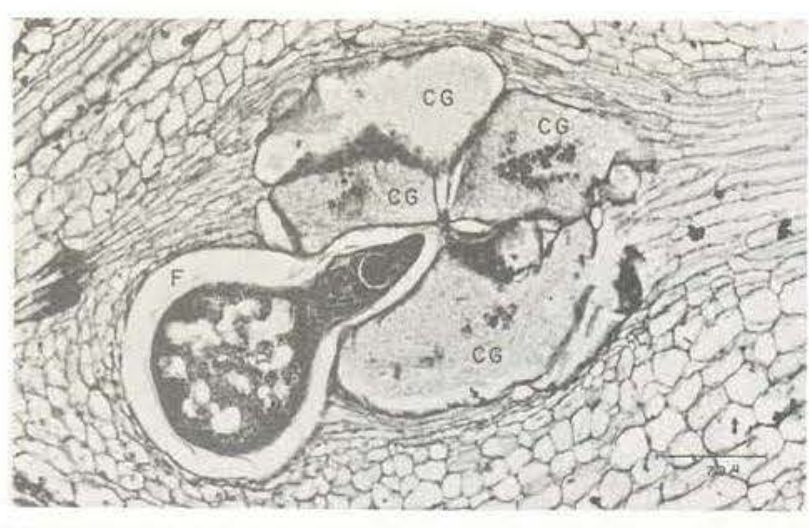

Fig. 5 - Secção longitudinal mostrando fêmea adulta $(F)$ com a parte anterior entre as células gigantes (CG)

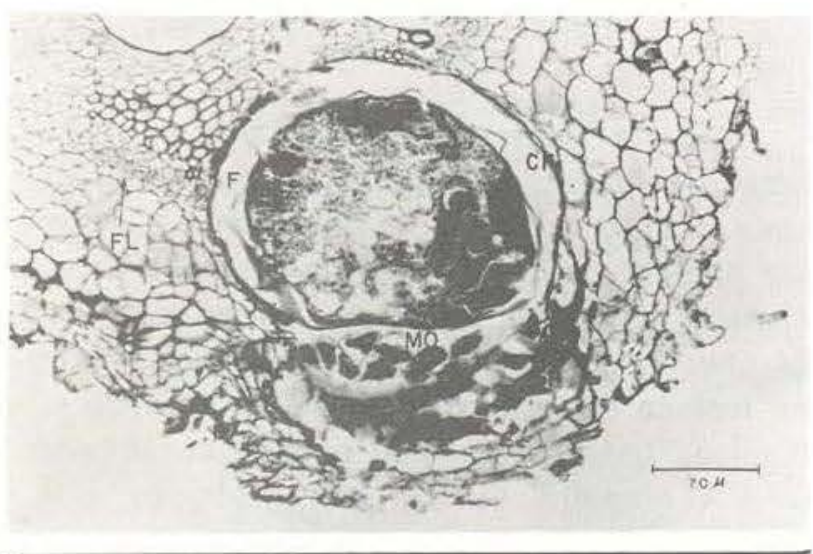

Fig. 6-Secçăo transversal da raiz destacando-se uma fêmea adulta $(F)$, a câmara da fêmea (CF) e a massa de ovos $(\mathrm{MO})$, além do floema $(\mathrm{FL})$.

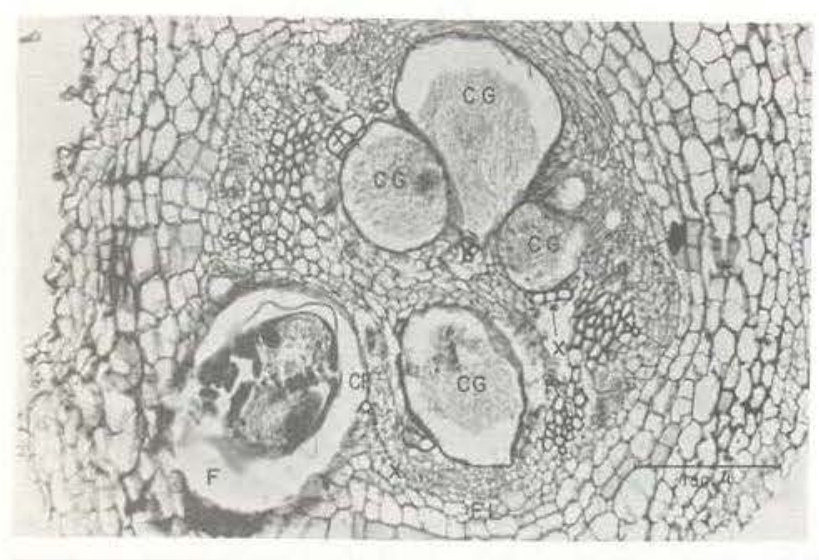

Fig. 7 - Secção transversal da raiz evidenciando a desorganização do cilindro vascular pela presença de células giganteš (CG) e de uma fêmea adulta $(F)$. $O$ xilema (X) mostra-se em contato com a câmara da fêmea (CF) e o floema (FL) justaposto às células gigantes (CG). ocorre preferencialmente da periferia para 0 centro da ooteca, sendo comum a migração de larvas de segundo estádio para outras áreas da raiz (Fig. 8).

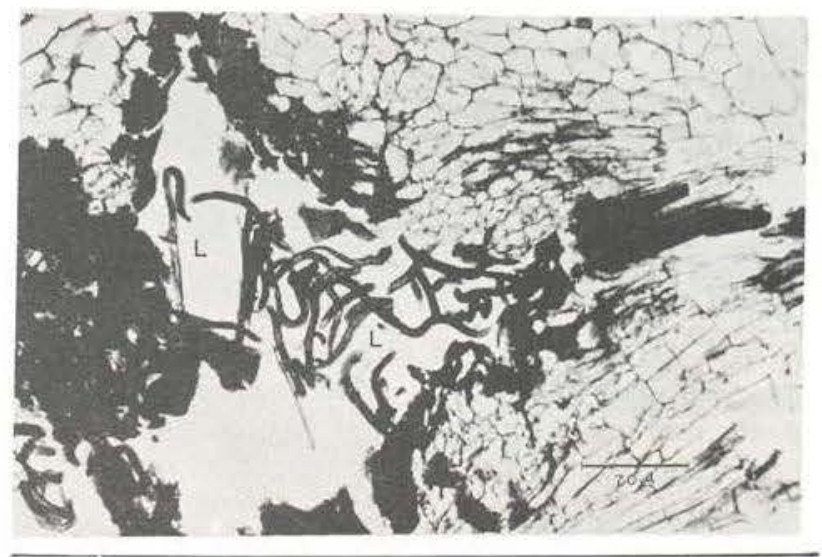

Fig. 8 - Eclosão e migração de larvas de segundo estádio (L) a partir de ooteca localizada no tecido cortical.

\section{Discussão E CONCLUSÕES}

O exame histológico do material em apreço evidenciou a preferência das larvas de segundo estádio em penetrarem pela região meristemática terminal, inter ou intracelularmente, localizando-se no pleroma paralelas ao eixo radicular (Fig. 1). Observações semeIhantes já haviam sido realizadas por outros pesquisadores (Dropkin \& Nelson, 1960 e Mendes, 1975).

A fêmea adulta situa sua cabeça no cilindro vascular, embutida entre as células gigantes, permanecendo com a parte posterior voltada para o córtex onde se verifica a deposição dos ovos. Sua posição em relação ao eixo da raíz é na maioria das vezes inclinada, quase paralela, mostrando-se raramente perpendicular (Fig. 5,6 e 7). Este aspecto não coincide com as suposições de Heald (1969) segundo as quais o posicionamento da fêmea adulta no interior da galha poderia estar relacionado a uma característica específica. Com efeito, variações desta ordem foram constatadas também por Mendes (1975) ao estudar o parasitismo de Meloidogyne exigua em raízes de Coffea arabica L. cv. Mundo Novo.

O mecanismo inicial de formaçăo das célu. las gigantes e seu desenvolvimento, segundo as secçộes histológicas observadas, parecem 
ocorrer pela dissolução de paredes e posterior fusão dos conteúdos celulares, a par de sucessivas mitoses sem citocineses. Conquanto não tenham sido observadas as células primordiais do sincício a delgada espessura da parede das células gigantes em alguns estádios de desenvolvimento, bem assim a ocorrência de áreas da parede celular em formação, reforçam a interpretação do surgimento das células gigantes por coalescência de células (Fig. 2). A exemplo dos resultados obtidos por Mendes (1975) não foi verificada, no presente estudo, a ocor rência de espessa camada de células comprimidas em torno das células gigantes, em vir tude de sua expansão. Ademais, a inexıstência de células gigantes jovens com paredes nitidamente delimitadas, bem como a observação de elementos do xilema conectados à massa sincicial sugerem uma negação à teoria de outros pesquisadores de que a formação das células gigantes se processaria a partir de uma única célula diploide original, através de repetidas mitoses sem citocineses.

Observou-se que os núcleos das células dissolvidas agregavam-se no interior do sincicio em desenvolvimento porém mantendo integras as suas membranas. No interior dos núcleos sobressaem proeminentes nucléolos, cir. cundados por um halo translúcido, destacando-os do restante da massa nuclear (Fig. 3). A ocorrência do halo translúcido já havia sido constatada por Mendes (1975). Contudo, não foi encontrada uma explicação plausivel para 0 fato. Em células gigantes degenerescentes, as quais exibiam dissoluções das paredes, a massa nuclear mostrava-se informe, igualmente degenerescente. Outro aspecto interessante relaciona-se com a resistência do xilema à dissolução e posterior englobamento pelas células gigantes em expansão, permanecendo aparentemente intato morfologicamente (Fig. 4). Fenômeno semelhante foi constatado por Birchfield (1964) em galhas de raizes de Echinochloa colonum infetadas por nematóides do gênero Meloidogyne, bem como por Mendes (1975) em galhas de raizes de Coffea arabica cv. Mundo Novo parasitadas por M. exigua.

As primeiras células afetadas antes do início de formação das células gigantes são as do pleroma, imediatamente próximos à cabeça do nematóide. Uma nítida hipertrofia verificàse nas células alteradas, seguida de entumescimento dos núcleos e divisōes celulares, aparentemente paralelas ao maior eixo da raiz (Fig. 1 e 2). As células assim formadas, ao que parece, invadem as células vizinhas por englobamento e dissoluçãa das paredes. Estes resultados assemelham-se aos de Christie (1936), Krusberg \& Nielsen (1958), Dropkin \& Nelson (1960) e Littrell (1966). Entretanto, muito embora o mencionado mecanismo de formação das células gigantes seja idêntico ao encontrado por Mendes (1975), o referido autor concluiu que a divisão das primeiras células, induzida pela secreção do nematóide, se processa periclinalmente à substância injetada sem mostrar qualquer dependência quanto à orientação do eixo radicular.

Năo obstante a localização de células gigantes na região cortical já ter sido mencionada em outros trabalhos (Christie, 1936 e Krusberg \& Nielsen, 1958) esta ocorrência não foi constatada neste estudo. Ao contrário, vigorosos sincícios formaram-se somente no cilindro vascular, ao que parece pela ampla disponibilidade de substâncias nutritivas da planta nesta região, nutrindo as células gigantes e, portanto, o próprio parasita (Fig. 7).

A presença do estilete da fêmea adulta no interior das células gigantes ou no tecido que circunda estas células, já observada por outros pesquisadores (Linford, 1938 e Mendes, 1975) não foi constatada no trabalho em questão. Entretanto, pareceu provável a alimenta. ção da fêmea pelo posicionamento do estilete entre as células gigantes. Observou-se ademais, a ocorrência de inúmeras fêmeas adultas exibindo proeminentes bulbos esofagianos, sugerindo uma acentuada atividade parasitária do nematóide (Fig. 5).

Com relação à eclosão das larvas verificou-se uma tendência direcionada da periferia para o centro da ooteca. Este fato sugere a localização na periferia da ooteca dos ovos em estádios de maturação mais avançados. Com efeito, parece lógico que à medida que ocorre a postura os ovos mais desenvolvidos são empurrados para as bordas da ooteca permanecendo os recém-formados nas áreas centrais da massa de ovos. Verificou-se, ainda, uma des- 
truiçăo dos tecidos corticais em torno da oote$\mathrm{ca}$, sugerindo um forte poder lisador da substância matriz que envolve os ovos (Fig. 6 e 8). Aliás, a atuação lisadora da substância matriz já havia sido constatada por Huang (1966) .

A ocorrência de vigorosos sincícios no cilindro vascular determinando seu colapso (Fig. 5), a ausência de necrose circundando as células gigantes ou o parasita (Fig. 7), a par da abundante produção de ovos (Fig. 6), caracterizam a elevada suscetibilidade da pimentado-reino - Piper nigrum L. var. Singapura à Meloidogyne incognita.

\section{SUMmary}

Histological observations made from roots of black pepper (Piper nigrum L.) variety Singapura parasitized by the root-knot nematode, Meloidogyne incognita (Kofoid \& White, 1919) Chitwod, 1949, revealed an interesting host - pathogen relationship.

It is concluded that the greatest penetration of the secondstage larvae occurred in the apical meristemmatic root region. The initial formation of the giant cells, as well as their development, seems to occur via (1) dissolution of the adjacent root cell walls with later fusion of the cellular contents and (2) successive mitoses without cytokinesis.

The high susceptibility of the black pepper variety Singapura to the root-knot nematode, $\mathbf{M}$. incognita, was characterized by vigorous syncytia formed in the vascular tissue causing its disorganization, lack of necrosis surrounding the adult female nematodes or syncytia, and abundant egg mass production.

\section{BIBLIOGRAFIA CITADA}

BIRCHFIELD, W.

1964 - Histopathology of nematode - induced galls of Echinochloa colonum. Phytopatholo-

BIRD, A. F. gy, 54(8) : 888 (abstrat.).

1974 - Plant response to root-knot rematode. Ann. Rev. Phytopathol., 12 : 69-85.

CHRISTIE, J. R.

1936 - The development of root-knot nematode galls. Phytopathology, 26(1): 1-22.

DRopkIN, V. H. \& NELSON, P. E.

1960 - The histopathology of root-knot nematode infeccions in soybeans. Phytopathology, $50(6): 442-47$.

ENDO, B. Y.

1971 - Nematode - induced syncytia (giant cells). Host - parasite relationships of Heteroderidae. In: ZuCKerMaN, B. M.; MAI, W. F. \& RoHDE, R. A. ed.: Plant Parasitic Nematodes. N. York, Academic Press. 2: $69-85$.
Freme, F. C. O.

1976 - Nematóides associados ao feijoeiro na Zona da Mata, Minas Gerais, e aspectos da relação entre alguns cultivares e as espécies Meloidogyne incognita e M. javanica (tese) de M.S.), Viçosa, U.F.V., Imprensa Universitária, $42 \mathrm{p}$.

HeAld, C. M.

1969 - Pathogenicity and histopathology of Meloidogyne graminis infecting "tifdwarf" bermudagrass roots. J. Nematol. 1(1) : 39-9.

HUANG, C. S.

1966 - Host - parasite relationships of the root-knot nematode in edible ginger - Phytopathology, 56(7) : 755-59.

Hung, C. S. \& Maggenti, A. R.

1969 - Mitotic aberrations and changes of developing giant cells in Vicia faba caused by root-knot nematode, Meloidogyne javanica. Phytopathology, 59(4) : 447-55.

1969 a - Wall modifications in developing giant cells of Vicia faba and Cucumis sativus induced by root-knot nematode, Meloidogyne javanica... Phytopathology, 59(7): 931-37.

HusSEy, R. S. \& BARKeR, K. R.

1973 - A comparison of methods for collecting inocula of Meloidogyne ssp. including a new technique. Plant. Dis. Reptr. 57(2) : 1025-28.

JoHANSEN, D. A.

1940 - Plant Microtechnique. New York, Mc GranHill Book Company 523 p. il.

Krusberg, L. R. \& Nielsen, L. W.

1958 - Pathogenesis of root-knot nematodes to the Porto Rico variety of sweet potato. Phytopathology. 48(1) : 30-9.

KRUSBERG, L. R.

1963 - Host response to nematode infeccion. Ann. Rev. Phytopathol., 1: 219-40.

LINFORD, M. B.

1937 - The feeding of the root-knot nematode in root-tissue and nutrien solution: Phytopathology, 27(8): 824-35.

LITTRELL, R. H.

1966 - Cellular responses of Hibiscus esculentus to Meloidogyne incognita acrita. Phytopa. thology, 56(5): 540-44.

MENDES, B. V.

1975 - Histopatologia de raízes de cafeeiro parasitadas por Meloidogyne exigua (Tese de M.S.), Viçosa, U.F.V. Imprensa Universitária, $54 \mathrm{p}$.

SASSER, J. N.

1971 - Introducción en los problemas del ataque de nemátodos en las plantas cultivadas universalmente y una sinopsis sobre los actuales métodos de control. Pflanzenschutz Nachrichten Bayer, 1 : 3-51.

(Aceito para publicaçäo em 25/11/77) 